\title{
Correction to "The Performance of Fertility Awareness-based Method Apps Marketed to Avoid Pregnancy"
}

In the above-mentioned article, ${ }^{1}$ the electronic version differs from the print version due to typos in Table 2. The only data affected were the apps that did not predict the fertile window. The electronic version on the Journal of the American Board of Family Medicine website has been corrected. We apologize for the error, and we regret any confusion or inconvenience it may have caused.

doi: 10.3122/jabfm.2016.06.160291

\section{Reference}

1. The Performance of Fertility Awareness-based Method Apps Marketed to Avoid Pregnancy. J Am Board Fam Med 2016;29:508-11. 